Colloque C2, suppl. au Journal de Physique II, Vo1. 1, septembre 1991

\title{
LPCVD SIC COATINGS ON UNIDIRECTIONAL CARBON FIBRE-YARNS : APPLICATION TO ALUMINIUM MATRIX COMPOSITES
}

\author{
M.H. VIDAL-SETIF and J.L. GÉRARD \\ ONERA, Materials Science Department, BP 72, F-92322 Chatilion, \\ France
}

\begin{abstract}
SiC}$ has been chosen as a diffusion barrier in carbon/aluminium metal matrix composites. P55 carbon tows are coated with a thin SiC layer applied in a continuous LPCVD process from a $\mathrm{Si}\left(\mathrm{CH}_{3}\right)_{4}-\mathrm{H}_{2}$ mixture, using a hot wall reactor. Deposition parameters (temperature, pressure, flow rates of reactants, fibres passing rate) are determined in order to ensure a good compromise between a thorough infiltration of the yarn and the carbon amount in the SiC. The coatings on the fibres are characterized in two ways : direct observation and evaluation of the coating thickness on metallographic cross sections of a mounted tow ; determination of the composition and thickness of the layer by EPMA on isolated fibres. Coated fibres are included in an aluminium matrix and a composite is fabricated by liquid phase hot pressing : the effect of the coating is observed and discussed. An optimization of the CVD infiltration parameters is still necessary to reduce the variations in coating thickness between the core of the yarn and the external fibres.
\end{abstract}

\section{INTRODUCTION}

Carbon fibre reinforced aluminium composites are good candidates for aeronautic and aerospace applications requiring specific high strength and stiffness together with dimensional stability at high temperature.

Efforts to achieve the potential strength of $\mathrm{C} / \mathrm{Al} \mathrm{MMC}$ using low cost and versatile processing route have generally yielded low values due to infiltration defects, misalignment of the fibres and particulary extensive chemical reaction between fibre and aluminium with the formation of a brittle reaction zone of aluminium carbide, $\mathrm{Al}_{4} \mathrm{C}_{3}$.

Coating graphite fibres with a thin $\mathrm{SiC}$ layer can prevent the fibre -matrix interaction in so far as the temperature is maintained below $650^{\circ} \mathrm{C}\left(10^{\circ} \mathrm{C}\right.$ below the melting point of pure aluminium) (1). Low pressure chemical vapor deposition appears as a convenient coating process for fibres since the fibre bundle can be coated continuously and each filament can be uniformly coated.

This work deals with an experimental study of SiC coating on P55 graphite fibre in a hot wall LPCVD reactor from a Si(CH$)_{4}-\mathrm{H}_{2}$ mixture. Attention is focused on the characterization of the coating (thickness, composition) directly on the fibres. Coated fibres are then incorporated in an aluminium matrix and the effect of the coating is discussed.

\section{EXPERIMENTAL DETAILS}

Fig 1 shows a schematic diagram of the experimental apparatus for chemical vapor deposition of $\mathrm{SiC}$. The hot wall reaction chamber consists of a vertical $20 \mathrm{~cm}$ long, $5 \mathrm{~cm}$ diameter graphite tube, inductively heated. Temperature is measured by a thermocouple located near the wall. The reactor and the inductor are both located in a watercooled stainless steel vacuum chamber with both ends equipped with a device for fibre transport and stockage. Four fibre bundles can be coated simultaneously and the direction of 


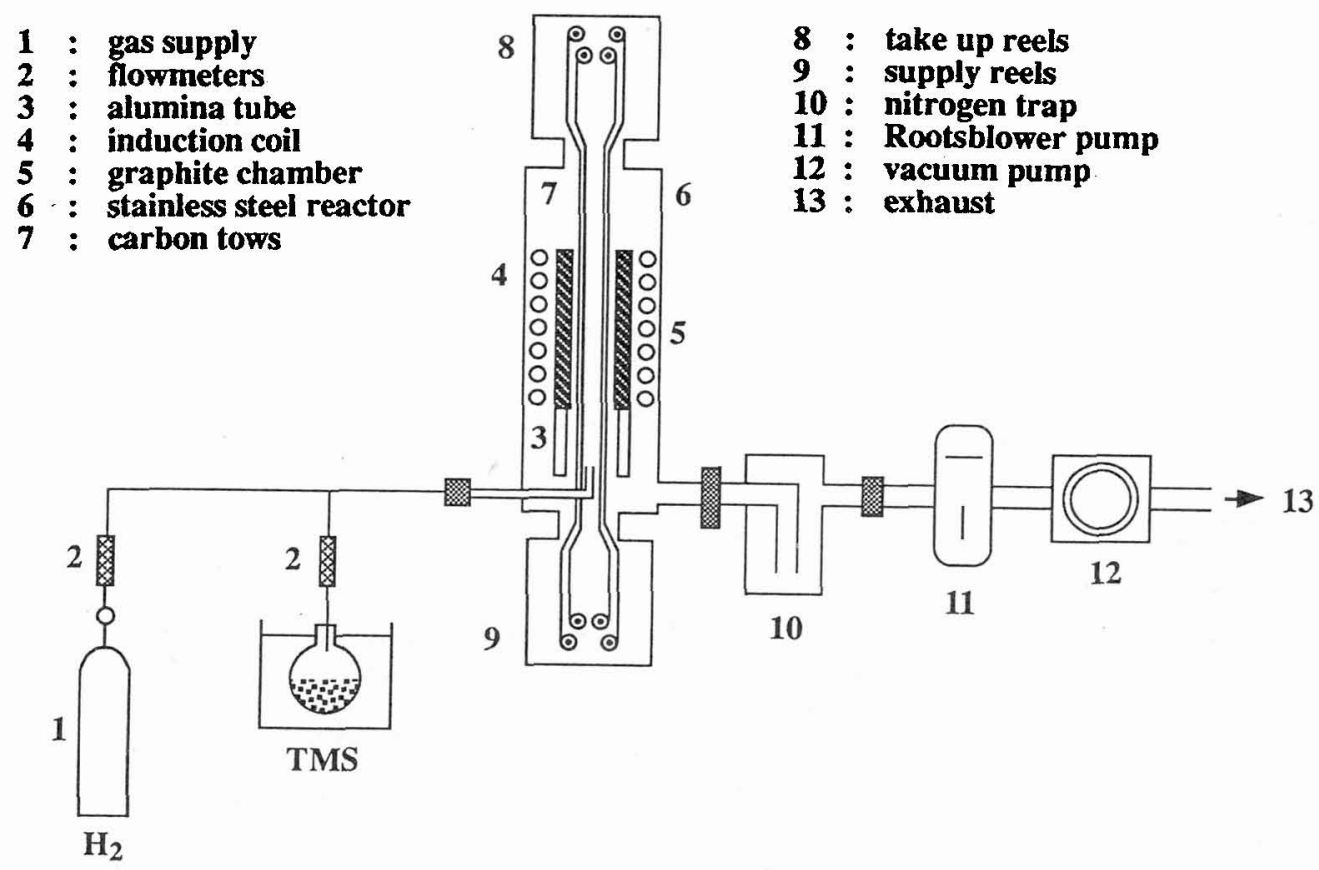

Fig. 1 : experimental set up for fibre coating.

passing can be reversed in order to deposit two successive coatings.

Low pressure is obtained with a couple primary pump-Roots blower pump protected by a powder filter and a liquid nitrogen cold trap. Tetramethylsilane (TMS) and hydrogen flow rates are controlled with mass flowmeters and the gas mixture is injected at the bottom of the reactor.

The kinetic study was made on flat graphite substrates ; deposition rate was determined by weight increase (linearity between weight increase and time has been checked). The crystalline phases in the coatings have been identified by $X$-ray. diffraction and their composition assessed by EPMA.

The employed carbon fibres were AMOCO P55, which are composed of 2000 filaments of $10 \mu \mathrm{m}$ in diameter.

Unidirectional metal matrix composite plates P55 /Al 1199 were fabricated using a liquid phase hot pressing process developed at ONERA (2): the processing temperature was $665^{\circ} \mathrm{C}$ with a hydrostatic pressure of $15 \mathrm{MPa}$ and the time of contact between liquid metal and fibre is about $10 \mathrm{~min}$.

\section{KINETIC STUDY}

A preliminary study was performed on flat substrates in order to define a range of CVD parameters (temperature, pressure, flow rates) favourable to the homogeneous infiltration of the tow.

Thermodynamics of the Si-C-H system has already been studied by Yoon (3) and the CVD phase diagram for the system $\mathrm{Si}\left(\mathrm{CH}_{3}\right)_{4}-\mathrm{H}_{2}$ determined. It is shown that a deposit of pure $\mathrm{SiC}$ is favoured by low temperature and high ratio $\left[\mathrm{H}_{2}\right]$ /TTMS] (high dilution of the reactant specie). On the other hand, experimetal results from Avigal et. al. (4) show that free carbon content in the coating decreases with an increase of temperature and that the deposition performed in hydrogen yields lower free carbon than in the presence of helium.

On the above considerations and as low pressure is required for infiltration (5), we have chosen to study the following experimental domain : 


\author{
$950^{\circ} \mathrm{C} \leq \mathrm{T} \leq 1150^{\circ} \mathrm{C}$ \\ 0.75 mbar $\leq \mathrm{P} \leq 6.6 \mathrm{mbar}$ \\ TMS flow rate, $\mathrm{D}_{\mathrm{TMS}}: 5,10,18 \mathrm{~cm}^{3} / \mathrm{min}$ \\ $\mathrm{H}_{2}$ flow rate, $\mathrm{D}_{\mathrm{H} 2}: 500,1000,1500 \mathrm{~cm}^{3} / \mathrm{min}$
}

\title{
3.1 Effect of temperature and pressure
}

The variation of the logarithmic $\mathrm{SiC}$ deposition rate versus reciprocal temperature for the ratio $\mathrm{D}_{\mathrm{H} 2} / \mathrm{D}_{\mathrm{TMS}}=1500 / 10$ is given in figure 2 . Classically, we can observe three regions corresponding to the three main categories of CVD kinetics control $(6,7):$ the linear variation range with a high negative slope value (apparent activation energy about $135 \mathrm{KJ} / \mathrm{mole}$ ) for surface kinetics control, mass transport control after the deviation from the straight line and nucleation control with a high positive slope value.

This Arrhenius plot shows that within the small experimental domain explored, a great variation in kinetics control occurs . At 0.75 mbar, the deposition takes place with a surface kinetics control all over the temperature range . At 1.5 mbar, surface kinetics control is observed until $1050^{\circ} \mathrm{C}$ and mass transport control at higher temperature. On the other hand, at $6.6 \mathrm{mbar}$, homogeneous nucleation is always predominant. It can be observed that over the temperature range studied, surface kinetics control is evident at lower total pressure and lower TMS flowrate (not shown).

\subsection{Effect of $\mathrm{H}_{2}$ dilution}

Figure 3 represents the dependence of the deposition rate on the $\mathrm{H}_{2}$ flow rate for different pressures ( $\mathrm{T}=1050^{\circ} \mathrm{C}$ and $\mathrm{TMS}$ flow rate, $\mathrm{D}_{\mathrm{TMS}}=10 \mathrm{~cm}^{3} / \mathrm{min}$ ).

At 0.75 mbar it is observed that $\mathrm{H}_{2}$ dilution allows the transition from mass transport control (where the deposition rate increases with $\mathrm{H}_{2}$ ffow rate) to surface kinetics control. In that case, a decrease in partial pressure of TMS occurs and so a decrease in the deposition rate. At $1.5 \mathrm{mbar}$, mass transport limitation is predominant whatever $\mathrm{H}_{2}$ flow rate. At $6.6 \mathrm{mbar}$, the effect of $\mathrm{H}_{2}$ is quite different. The decrease in growth rate at low $\mathrm{H}_{2}$ flow rate is attributed to homogeneous nucleation process. Then, as $\mathrm{H}_{2}$ flowrate is increased, the velocity of gas is increased decrasing their residence time and so the probability of reaction in the gas phase. The deposition mechanism changes to mass transport control.

\subsection{Conclusion}

By performing the deposition at low pressure ( $P \leq 1.5 \mathrm{mbar}$ ), low TMS flow rate $\left(D_{T M S} \leq 10 \mathrm{~cm}^{3} / \mathrm{min}\right.$ ) and with a high dilution by $\mathrm{H}_{2}\left(\left[\mathrm{H}_{2}\right] /[\mathrm{TMS}]>500\right)$, we can expect to minimize homogeneous chemical reaction and be able to stay in a region of surface kinetics control in the range of temperature $\left(900^{\circ} \mathrm{C}\right.$ $1050^{\circ} \mathrm{C}$ ).

\subsection{Analytical results}

Three coatings about $10 \mu \mathrm{m}$ thick deposited at 950,1020 and $1050^{\circ} \mathrm{C}$, with a ratio of $\mathrm{D}_{\mathrm{H} 2} / \mathrm{D}_{\mathrm{TMS}}=$ $1500 / 10$ and a pressure of 0.75 mbars have been analysed. On the three coatings, the XRD diffraction patterns reveal the presence of $\beta \mathrm{SiC}$. The composition of the coatings was determined by EPMA using a PAP correction model and calibration by a Si standard $(\mathrm{SiK} \alpha)(8)$ : the composition of the SiC coating was determined to be a 1:1 ratio of Si to $\mathrm{C}$ atoms (accuracy of the results at 1at\%).

\section{APPLICATION TO CARBON FIBRE INFILTRATION}

As we can consider a fibre bundle as a porous medium (the void space between the fibres varying from zero to several microns) it is possible to apply results of chemical vapor infiltration $(9,10)$. In order to achieve a good uniformity in thickness and composition of the coating, it is necessary to be in a region of surface kinetics control with a deposition rate low enough to allow the diffusion of gaseous species inside the yarn. Unless, premature coating and bridging of the outer monofilaments will be observed creating a shell round the tow. Low pressure, low temperature and high ratio $\left[\mathrm{H}_{2}\right] /[\mathrm{TMS}]$ are therefore required.

Within the region of surface kinetics control defined in 3.3, the following domain has been investigated: 


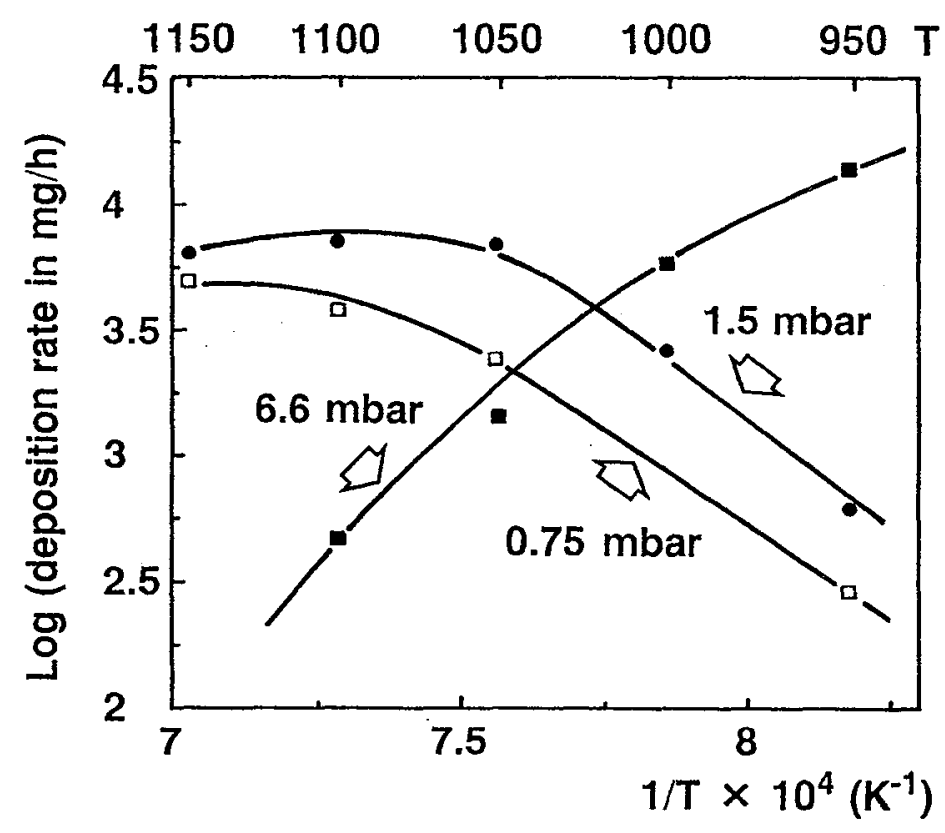

Fig. 2 : Arrhenius plot for $\mathrm{SiC}$ deposition $\left(\mathrm{D}_{\mathrm{H} 2} / \mathrm{D}_{\mathrm{TMS}}=1500 / 10\right)$.

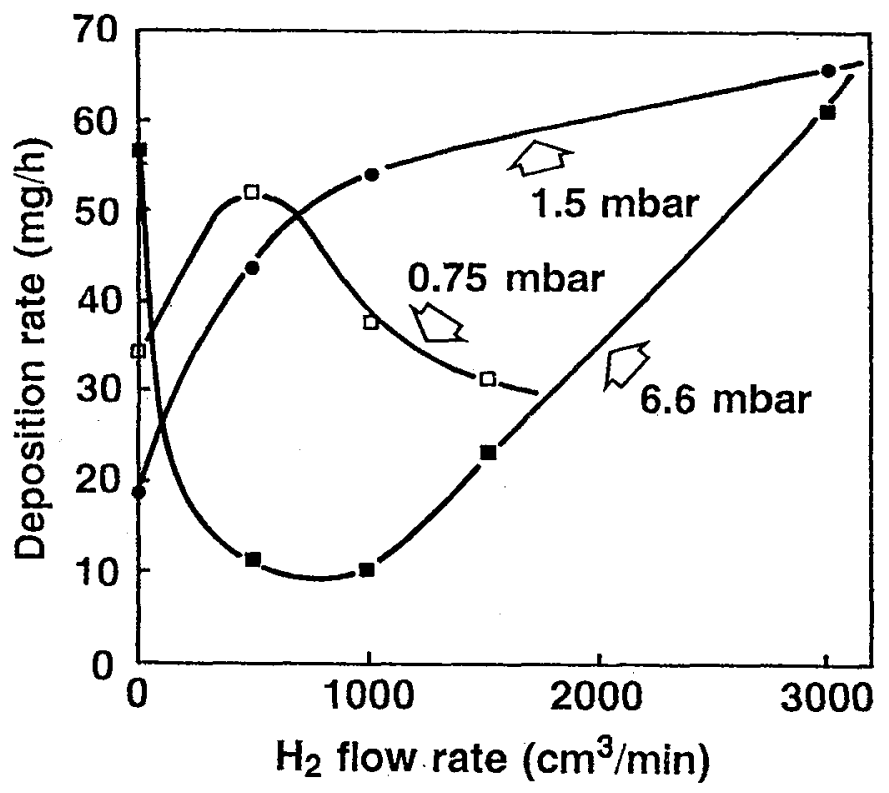

Fig.3 : influence of carrier gas $\mathrm{H}_{2}$. 


$$
\begin{aligned}
& 950^{\circ} \mathrm{C} \leq \mathrm{T} \leq 1050^{\circ} \mathrm{C} \\
& \mathrm{P}=0.75 \mathrm{mbar} \\
& \mathrm{D}_{\mathrm{H} 2} / \mathrm{D}_{\mathrm{TMS}}=1500 / 10
\end{aligned}
$$

At first coatings have been performed on a fixed tow during three hours. So, deposits are thick enough to be observed by optical microscopy.

Figure 4 shows metallographic cross sections of part of carbon fibre tow coated at $950^{\circ} \mathrm{C}$ ( the coated tow has been electrolytically coated with nickel and etched in order to reveal the coating). On figure $4 \mathrm{a}$, a general view of the yarn showing fibres from the periphery and fibres from the core : the infiltration has been successfull as inner fibres are coated. At a higher magnification (figure 4b), it can be seen that only the fibres touching each other are not individually coated; small bridges link two or three fibres since the bundle is not entirely spread out in the reactor. This is difficult to avoid. When fibres are not in contact, the coating thickness seems homogeneous from one fibre to another. Figure 5 is an SEM micrograph of a coated fibre from the core: the coating is homogeneous and is about $600 \mathrm{~nm}$ thick.

On the other hand, at the periphery of the yarn, the coatings are thick and unsymmetrical. It was also observed that the coating thickness corresponds to the coating growth rate on the flat graphite substrate at this same temperature (about $7 \mu \mathrm{m} / \mathrm{h}$ ). This inhomogeneity between the periphery and the core of the yarn is typical of different mass transport mechanisms encountered during the infiltration of porous media (11). Figure 6, where the original arrangement of fibres in the tow has been preserved illustrates this quite well . For the first external layer of fibres, no pore exists and the reactant can easily access the surface of the fibres. The coating growth rate is limited by the chemical reaction rate (surface kinetics control). On the other hand, in the core of the tow, the void space between adjacent fibres defines pores of small diameter (less than $5 \mu \mathrm{m}$ ), limiting the diffusion of gaseous species. The process is mass transport controlled with a much lower coating growth rate $(600 \mathrm{~nm} / \mathrm{h})$. In this case, mass transport is governed by Knudsen diffusion whose coefficient is proportional to small diameter pores and is much lower than the Fick diffusion coefficient . For the second external layer of fibres, mass transfer will be governed by Fick diffusion as far as the coating thickness on the first layer of fibres allows it. As the coating thickness increases on the first layer, the diameter of the pore and, therefore, the access to the second layer of fibres decreases until reaching a critical value corresponding to the transition Fick diffusionKnudsen diffusion. From then on, the coating growth rate and the coating thickness will decrease.

This inhomogeneity in thickness is increased by the long duration of the coating experiment. When external fibres are entirely bridged (within about one hour or two), access to the core is prevented and only the coating on the external fibres grows on. Figure 7 shows a metallographic cross section of a bundle coated continuously at a rate of $20 \mathrm{~cm} / \mathrm{h}$. The inhomogeneity in thickness is reduced but still exists as external coatings are $2 \mu \mathrm{m}$ thick and inner coatings about $400 \mathrm{~nm}$ thick. The coating doesn't adhere well to the fibre as some spalling is often observed for thick coatings during continuous experiments (spooling effect).

\section{ANALYTICAL RESULTS}

A coating on P55 fibre deposited at $950^{\circ} \mathrm{C}$ and $60 \mathrm{~cm} / \mathrm{h}$ has been analysed by EPMA using a combined determination of layer thickness and composition with a PAP correction model (12) (calibration by standards of $\mathrm{Si}(\mathrm{Si} \mathrm{K} \alpha)$ and $\mathrm{SiC}(\mathrm{C} \mathrm{K} \alpha)$ ). The coating can be described by a $180 \mathrm{~nm}( \pm 20 \mathrm{~nm})$ SiC layer of atomic composition $50 \%, 50 \%$, confirming the results obtained on flat graphite substrate.

\section{APPLICATION TO MMC}

Plates of composites Al1199/SiC/C were fabricated using fibres coated continuouly (passing rate $60 \mathrm{~cm}$ h) at $950^{\circ} \mathrm{C}$ and compared to Al 1199 /uncoated P55.

Figure 8 shows transverse cross sections of composites plates with uncoated fibres (a) and coated fibres (b). At the resolution of optical microscopy $(0.5 \mu \mathrm{m})$, the coating seems effective as a diffusion barrier as a big decrease in the amount of $\mathrm{Al}_{4} \mathrm{C}_{3}$ formed at the interface fibre-matrix is observed. However, at the resolution of transmission electron microscopy, the presence of $\mathrm{Al}_{4} \mathrm{C}_{3}$ is detected. Different kinds of defects can be found in the plates. When fibres come from the periphery of the yarn where the coating is thick and spalled, $\mathrm{Al}$ has penetrated between the fiber and the coating giving formation to $\mathrm{Al}_{4} \mathrm{C}_{3}$ (figure $9 \mathrm{a}$ ) ; isolated formation of $\mathrm{Al}_{4} \mathrm{C}_{3}$ is observed at the interface fibre-matrix (figure9b) corresponding to a locally thinner coating may be due to a very close-packed arrangement of fibres. 


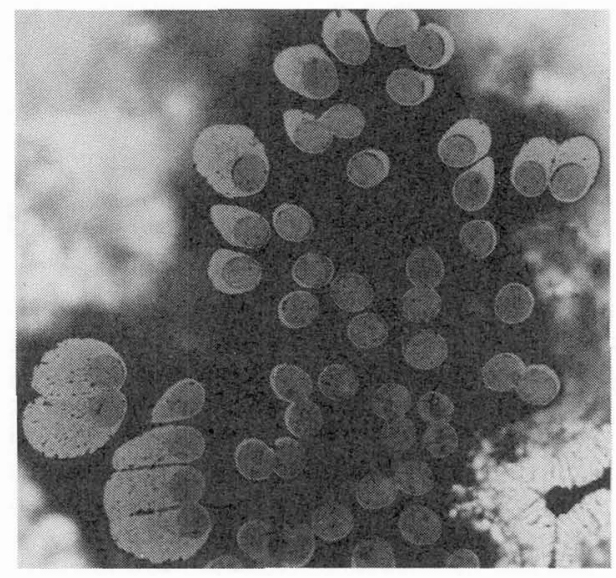

4a : external fibres

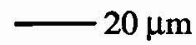

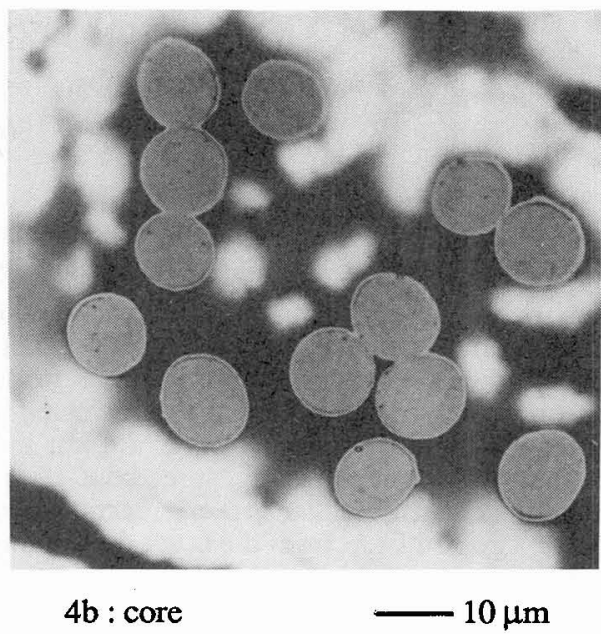

Fig. 4 : metallographic cross sections of a SiC coated tow, $\mathrm{T}=950^{\circ} \mathrm{C}$.

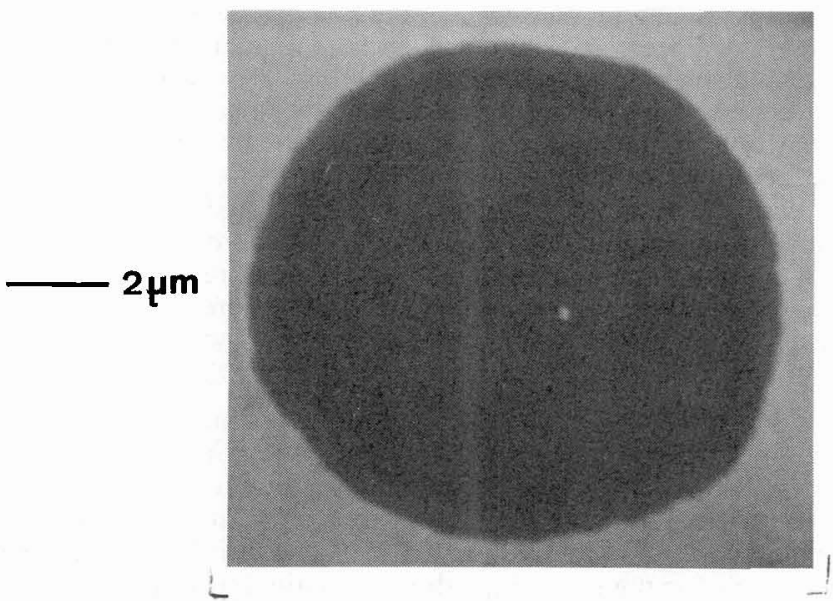

Fig. 5 : SEM micrograph of a coated fibre (core of the yarn).

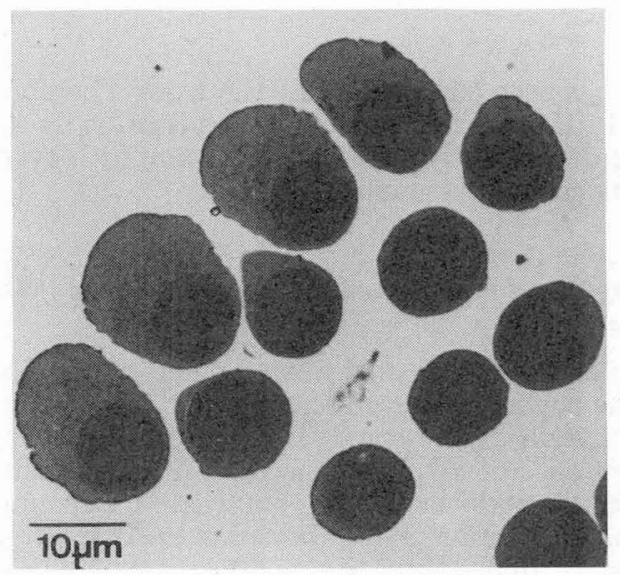

Fig. 6 : illustration of mass transport mechanisms.

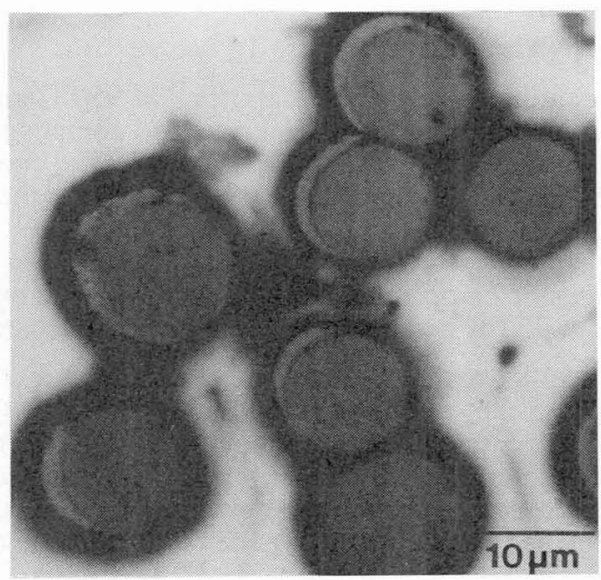

Fig. 7 : continuous experiment, $20 \mathrm{~cm} / \mathrm{h}$ 


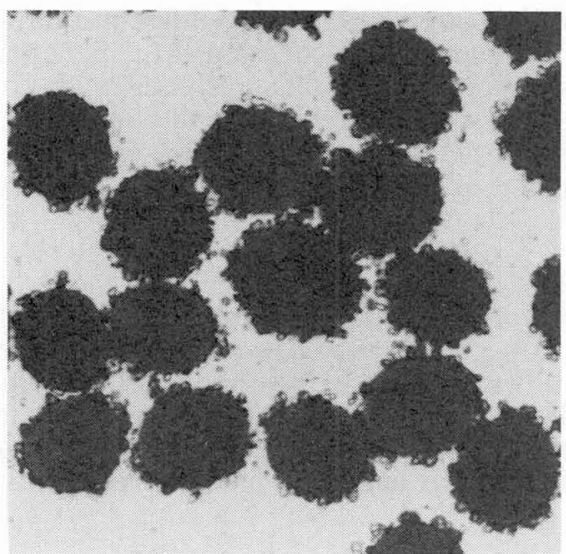

8a : uncoated fibres

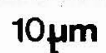

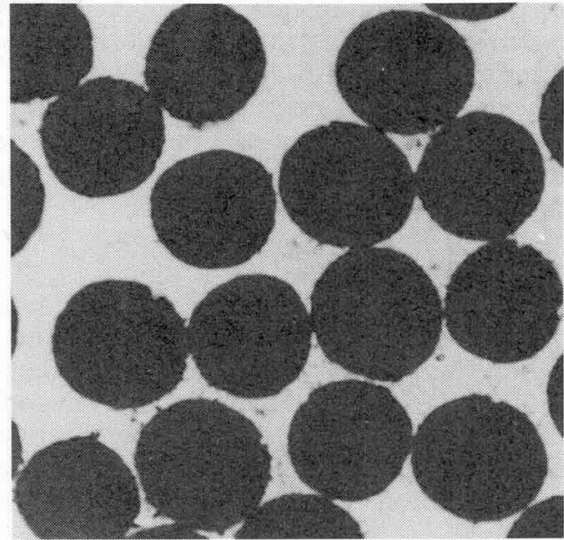

$8 \mathrm{~b}:$ coated fibres $10 \mu \mathrm{m}$

Fig. 8 : metallographic cross sections of Al 1199/P55 composite
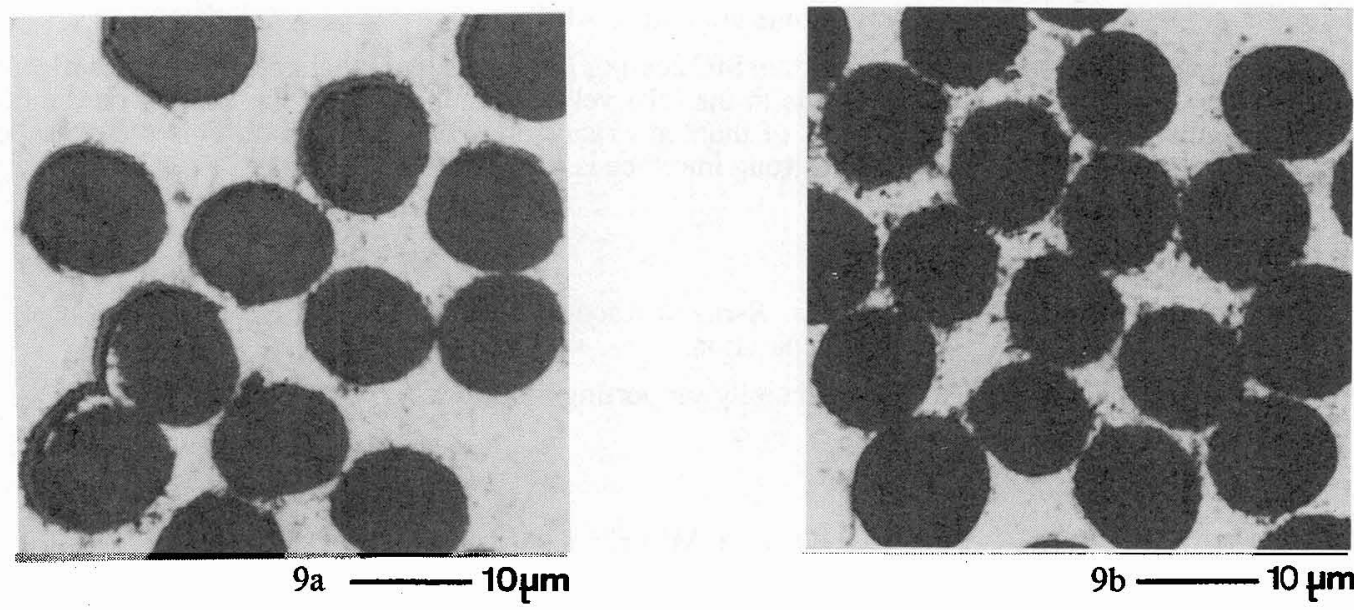

Fig.9 : typical defects in Al 1199/SiC/P55 composite

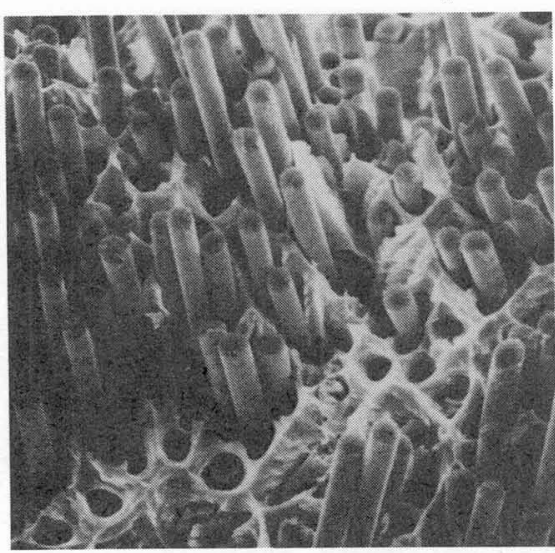

$10 \mathrm{a}$

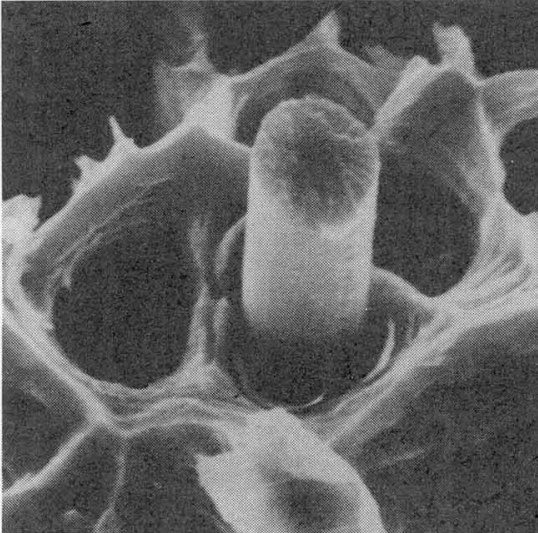

$10 \mathrm{~b}$

$10 \mu \mathrm{m}$

Fig.10 : SEM micrograph of the fracture surface of Al 1199/SiC/P55 composite. 
In spite of of these defects, interesting observations from tensile tests have been made . Figure 10 (a) shows a typical fracture surface of this composite. Where fibres are uncoated, a very flat fracture surface is obtained indicating catastrophic crack propagation. Here, on the other hand, a rugged fracture surface is obtained, indicating that fibres ruptures are followed by local interfacial decohesion. At a higher magnification, figure $10 \mathrm{~b}$, it can be observed that the coating is responsible for this crack deflection : the decohesion takes place at the interface fibre-coating due to a weak adhesion between the fibre and the $\mathrm{SiC}$ layer. This pull- out of fibres is evenly distributed throughout the plate confirming the efficiency of the coating infiltration within the tow. In that case, the coating has played a role of mechanical fuse, isolating the fibre from damage.

\section{Conclusion}

P55 carbon fibre bundle has been coated in a continuous way with $\mathrm{SiC}$ by $\mathrm{LPCVD}$ from a $\mathrm{Si}\left(\mathrm{CH}_{3}\right)_{4}-\mathrm{H}_{2}$ mixture. The inside of the yarn is effectively coated and the coating is constituted of pure SiC. Thickness inhomogeneity between the outside and the core of the yarn still remains. Work is in progress to improve the homogeneity by modifying the CVD conditions (in particular an increase in $\mathrm{H}_{2}$ flow rate, leading to a further decrease of the coating growth rate, will delay the formation of bridges between fibres). It could be expected also to find a better compromise for CVD parameters using analytical modeling of chemical vapor infiltration (10).

The efficiency of the coating in reducing the detrimental reaction between carbon fibre and liquid aluminium has been verified. However, some $\mathrm{Al}_{4} \mathrm{C}_{3}$ still remains, as a result of the interaction of $\mathrm{SiC}$ with aluminium still the processing temperature is high $\left(665^{\circ} \mathrm{C}\right)$ and the exposure time between the liquid matrix and the fibre is long.The use of an alloy instead of pure aluminium, allowing a lower processing temperature should lead to a further decrease of the amount of $\mathrm{Al}_{4} \mathrm{C}_{3}$.

Observations on fracture surfaces show that the $\mathrm{SiC}$ coating plays a role of mechanical fuse by deflecting cracks initiated in fibres. This property is due to the relatively poor adherence of the coating on the fibre caused by a mismatch between coefficients of thermal expansion of $\mathrm{SiC}$ and carbon.This seems to be a good opportunity for C/Al system where a strong interface is not required.

\section{ACKNLOWLEDGEMENT}

We gratefully acknowledge Dr. C. DIOT for X-ray diffraction analysis, Y. PIOCHE for EPMA analysis and M. RAFFESTIN for metallographic preparation.

The authors wish to thank D.R.E.T for financially supporting this work.

\section{REFERENCES}

/1/ VIALA J.C., FORTIER P. and BOUIX J., J. Mater. Sci., 25 (1990) 1842-1850.

12/ RABINOVITCH M., DAUX J. C., RAVIART J. L. and MEVREL R.,Proc. ECCM4, Stuttgart, West Germany (1990), EACM and Elsevier Applied Science Publisher Ltd ed, 405-410.

13/ YOON K. H., Thesis (1986) University of Limoges, France.

14/ AVIGAL Y., SCHIEBER P. and LEVIN R., J. Cryst. Growth, 24/25 (1974) 188-192.

15/ HERAUD L., COTTERET J., BONNET C., CHRISTIN F., NASLAIN R. and HAGENMUL LER P., French Patent $\mathbf{n}^{\circ} 7726979$ (1977).

16/ CARLSSON J. O., Thin Solid Films, 130 (1985) 261-282.

7/ VAN DEN BREKEL C. H. J., Philips Res. Repts., 32 (1977) 118-133.

/8/ POUCHOU J. L. and PICHOIR F., Rech. Aerosp. 3 (1984) 167.

19/ AGGOUR L., FITZER E., IGNOTOWITZ E. and SAHEBKAR M., Carbon, 12 (1974) 358-362.

/10/ TAI N. H. and CHOU T.W., J. Am. Ceram. Soc., 72(3) (1989) 414-420.

/11/ ROSSIGNOL J.Y., LANGLAIS F. and NASLAIN R., Chemical Vapor Deposition, Proc. CV9, Cincinnatti (Mc. D. Robinson et al., eds.), The electrochem. soc., Pennington (1984) 596-614.

112/ POUCHOU J. L. and PICHOIR F., J. Microsc. Spectrosc. Electron., 11 (1986) 229. 